\title{
ANÁLISE DO AMBIENTE INSTITUCIONAL E ORGANIZACIONAL DA PISCICULTURA NO ESTADO DE MATO GROSSO DO SUL ${ }^{1}$
}

\author{
Mônica Ferreira Satolani ${ }^{2}$ \\ Cynthia Cândida Corrêa ${ }^{3}$ \\ Mayra Batista Bitencourt Fagundes ${ }^{4}$
}

\begin{abstract}
Resumo - A piscicultura pode ser uma alavanca para o desenvolvimento social e econômico, visto que possibilita o aproveitamento efetivo dos recursos naturais locais. Entretanto, existem inúmeras variáveis que condicionam ou afetam o sucesso de um empreendimento rural. Nesse sentido, este estudo objetivou demonstrar os fatores organizacionais e institucionais capazes de afetar o desenvolvimento da piscicultura no estado de Mato Grosso do Sul. Para isso, buscou-se investigar como as instituições que compõem os ambientes organizacional e institucional afetam diretamente e influenciam o crescimento ou o direcionamento da piscicultura no Estado. Utilizou-se, como técnica de coleta de dados, a análise documental, considerando informações coletadas diretamente em instituições ligadas à piscicultura como importante fornecedor de dados, além de outras instituições públicas. Pode-se concluir que a piscicultura no estado de Mato Grosso do Sul apresenta grandes possibilidades de crescimento e ampliação, além de órgãos e instituições que dão suporte e desenvolvem a atividade no estado, desde que gargalos ainda existentes, como a dificuldade de acesso aos financiamentos disponíveis ou a falta de profissionalização dos empreendimentos, possam ser sanados.
\end{abstract}

Palavras chave: Piscicultura, ambiente institucional, ambiente organizacional.

Recebido em: 03/06/2008 Aceito em: 19/08/08

2 Mestranda em Agronegócios - Universidade Federal de Mato Grosso do Sul - UFSM Email: monicasatolani@hotmail.com

3 Mestranda em Agronegócios - Universidade Federal de Mato Grosso do Sul - UFSM. E-mail: cynthiacandida@yahoo.com.br

4 Doutora em Economia Aplicada e professora titular da Universidade Federal De Mato Grosso do Sul - UFSM. E-mail: mayra_bitencourt@yahoo.com.br 


\section{Introdução}

No Brasil, a piscicultura teve início na década de 30, com os trabalhos pioneiros de Rudolph Von Ihering, em Cachoeira de Emas - SP, sobre a prática de propagação artificial de peixes de piracema. Porém a falta de incentivo inicial fez com que a atividade adentrasse em um período de latência e, somente a partir da década de 70, retomasse o impulso, com desenvolvimento de pesquisas sobre a criação de espécies de peixes nacionais (Cyrino, 1996). De acordo com Zimmermann (2001), até meados de 1980 a piscicultura ainda não havia se tornado uma atividade econômica e socialmente significativa.

Segundo Souza (2002), na década de 90, o crescimento acelerou- se no Brasil e passou a ser uma atividade de importância econômica em um país que possui um dos maiores potenciais hídricos do mundo, clima tropical e espécies nativas de peixes que apresentam excelente aptidão para piscicultura. Paralelamente a isso, ocorreu uma estruturação nos segmentos de suporte, produção de alevinos, insumos e equipamentos.

O estado de Mato Grosso do Sul possui características favoráveis ao desenvolvimento da piscicultura. Grande parte do Pantanal encontra-se no estado e caracteriza-se por ser uma imensa planície alagável, com cerca de $140.000 \mathrm{~km} 2$, e por abrigar abundante quantidade de espécies de peixes (EMBRAPA PANTANAL, 2007).

Há cerca de 260 espécies de peixes catalogados, que são mantidos graças ao bom estado de conservação da planície pantaneira e tornam-se uma alternativa econômica altamente promissora à região.

A piscicultura pode ser uma alavanca de desenvolvimento social e econômico, visto que possibilita o aproveitamento efetivo dos recursos naturais locais, principalmente os hídricos, e a criação de postos de trabalhos assalariados. Entretanto, existem inúmeras variáveis que condicionam ou afetam o sucesso de um empreendimento rural. 
À medida que muda o ambiente institucional ${ }^{5}$ e organizacional ${ }^{6}$, altera-se o ambiente competitivo, e todos os agentes econômicos envolvidos no processo produtivo do agronegócio são afetados. No caso da piscicultura, os ambientes institucionais (a legislação, as políticas públicas de financiamento e as variáveis macroeconômicas) e organizacionais (grupos políticos, econômicos, sociais e organizações educativas) afetam as variáveis econômicas. No entanto, não se sabe quais são os fatores que mais influenciam o desenvolvimento do agronegócio da piscicultura em Mato Grosso do Sul.

Nesse contexto, o problema a ser analisado é: Quais são os fatores organizacionais e institucionais que podem afetar o desenvolvimento da piscicultura no estado de Mato Grosso do Sul?

Portanto, este estudo objetivou refletir sobre o papel das instituições e organizações no desenvolvimento da piscicultura no estado do Mato Grosso do Sul. Busca-se, assim, a análise dos agentes que compõem o ambiente organizacional, como as empresas de pesquisa e extensão, instituições financeiras e organizações, entre outros, que regulam ou determinam a ação dos agentes produtivos, por meio do conjunto de regras formais relacionadas com tributos, incentivos, defesa da concorrência e meio ambiente, e os ambientes institucionais, compostos por legislação, políticas públicas de financiamento e variáveis macroeconômicas.

Dada a relevância econômica da piscicultura para o estado de Mato Grosso do Sul, observa-se que, academicamente, pouco se tem refletido sobre a atividade. Trabalhos recentes têm enfocado a teoria da Nova Economia Institucional para piscicultura, como os realizados por Leão (2008) e Prochmann (2007), porém enfatizam apenas as relações de

\footnotetext{
Ambiente Institucional: Conjunto de normas e regras que delimitam as ações estabelecidas pelo homem, disciplinando suas ações com seus semelhantes e com o mundo, podendo também regulamentar outras instituições, definindo os critérios que serão estabelecidos por meio de formas e regras.

6 Ambiente Organizacional: São organizações que congregam grupos de indivíduos vinculados a algum propósito comum ou afinidade em seus objetivos. Esses julgam que ações conjuntas têm um sinergismo maior do que cada um trabalhando isoladamente, ou seja, a união das ações proporciona maior organização para atingir os objetivos.
} 
governança e as convenções para a piscicultura do estado. Ainda não são encontrados trabalhos que abordam os ambientes institucionais e organizacionais, razão pela qual o presente artigo contribui para a economia, por meio de uma análise precisa e crítica dos ambientes institucionais e organizacionais presentes na piscicultura.

\section{Referencial teórico}

\subsection{Nova economia institucional}

A Nova Economia Institucional (NEI) tem a preocupação de estudar as relações entre instituições e eficiência, e há, para isso, duas vertentes que abordam esses assuntos: o ambiente institucional e as instituições de governança. A primeira corrente analisa o papel das instituições, ao investigar os efeitos das mudanças no ambiente institucional sobre o resultado econômico ou sobre as teorias que criam as instituições, dedicando-se mais especificamente ao estudo das "regras do jogo". A segunda estuda as transações, com enfoque nas estruturas de governança, que coordenam os agentes econômicos. As regras gerais da sociedade, nesse enfoque, são consideradas como dadas. Esta última corrente busca identificar como as diferentes estruturas de governança lidam com os custos de transação, com níveis distintos de eficiência (Williamson, 2000).

Uma empresa, ao elaborar um produto, tem um custo de produção para processar e combinar os insumos, usando uma tecnologia até finalizá-lo e comercializá-lo. Esse custo pode ser discriminado em custo de transformação e custo de transação. De acordo com Leão (2008 apud Williamson, 1996), este último são os custos para conduzir um sistema econômico.

Os custos de transação podem ser definidos em quatro níveis: o primeiro relaciona-se com os custos de construção e negociação dos contratos; o segundo envolve os custos para medir e monitorar os direitos de propriedade existentes no contrato. Esse nível incorpora os custos de 
observação dos contratos ao longo do tempo para seu desempenho e atende às expectativas das partes que fizeram a transação. $\mathrm{O}$ terceiro nível engloba os custos de manter e fazer executar os contratos internos e externos da firma. O quarto e o último nível relaciona-se com os custos de adaptação que os agentes sofrem com as mudanças ambientais (Farina, 1999). Quanto mais rápida for a adaptação, menos custos de transação existirão, resultando em lucros maiores.

O ambiente institucional tem um enfoque macroanalítico, já que trabalha com variáveis relacionadas com política, legislação e instituições que formam e estruturam os aparatos regimentais de uma sociedade. A instituição de governança tem um enfoque microanálitico, já que o interesse maior é trabalhar com as organizações da firma e mercado, e com os contratos (Farina et al., 1997).

Cabe ressaltar que este trabalho constitui uma análise baseada no ambiente institucional e organizacional, de acordo com os pressupostos da teoria da Nova Economia Institucional, proposta por Williamson (2000). De acordo com os pressupostos desta teoria, investigaram-se os efeitos das mudanças nos ambientes institucionais e organizacionais sobre o resultado econômico da piscicultura no estado de Mato Grosso do Sul.

\subsection{Ambiente institucional}

O ambiente institucional constitui o que alguns autores definem de "regras do jogo", que promovem o desenvolvimento das atividades econômicas, bem como as ações políticas, legais e sociais que governam a base da produção, troca e distribuição (Williamson, 2000). Os conjuntos de normas e regras delimitam as ações estabelecidas pelo homem, disciplinando suas ações com seus semelhantes e com o mundo, podendo também regulamentar outras instituições, definindo os critérios que serão estabelecidos por meio das duas formas de regras - formais ou informais. 
Esse ambiente ganha importância quando os custos de transação não podem ser negligenciados. Se não existir nenhum sistema com este custo nulo, as instituições devem ser analisadas e consideradas (North, 1994). As instituições criam e delimitam o ambiente onde ocorrerá a transação e onde as organizações irão atuar.

Segundo North (1994), as instituições representam, ao longo da história, a manutenção da ordem e a redução das incertezas nas sociedades. As instituições com restrições econômicas definem o conjunto de alternativas e oportunidades a que os agentes econômicos se sujeitam na sociedade, favorecendo, ou não, a elevação dos custos de transação, transformação e lucratividade, existentes no sistema econômico.

A evolução institucional leva também a uma forte relação de dependência com o grau de sua complexidade, seja em relação à configuração estrutural, seja em relação aos propósitos a que deve servir. Matthews (1986) acredita que, ao mesmo tempo que a inércia é importante para a instituição, é ela que motiva a mudança desta, incorporando-se à trajetória de dependência de novas concepções institucionais, tornando-se mais complexa e, num segundo momento, novamente inerte, o que assegura a estabilidade.

\subsection{Ambiente organizacional}

As organizações congregam grupos de indivíduos vinculados a algum propósito comum ou com afinidade em seus objetivos. Eles julgam que ações conjuntas têm sinergismo maior do que se cada um trabalhasse isoladamente, ou seja, a união das ações proporciona maior organização para atingir os objetivos, quando são coordenadas.

As organizações podem ser constituídos de grupos políticos (partidos políticos, Câmara dos Deputados, Senado e órgãos reguladores) ou econômicos, empresas, sindicatos, cooperativas, associações rurais, entre outros. Os grupos sociais podem ser exemplificados por igrejas, clubes 
de serviço, associações desportivas, organizações não-governamentais, mais comumente conhecidas como ONGs, e organizações educativas (escolas, universidades, centros de treinamento). As oportunidades captadas pelas organizações são fornecidas pelas estruturas institucionais.

A percepção de mudanças é resultado de escolhas cotidianas, elaboradas pelas organizações, as quais podem ser realizadas com a alteração de contratos entre indivíduos e organizações. Há ocasiões em que a recontratação requer alterações nas regras preexistentes, desde que os agentes percebam a possibilidade de ganho com a mudança, ainda que, por vezes, a fonte de mudança institucional seja o aprendizado dos agentes, indivíduos ou empresários organizados que constroem novos modelos mentais para decifrar as mudanças no ambiente (North, 1994).

As organizações somente conseguirão atingir os resultados esperados se houver a coordenação das ações de seus membros. O mercado, por si só, é um poderoso mecanismo de coordenação das ações individuais. Nessa situação, cada indivíduo age de forma independente e autônoma, decidindo quais serão seus planos de ação. A força do mercado está no fato de que, por meio dele, os mais distintos objetivos podem ser perseguidos, mas ninguém tem a capacidade de impor os seus próprios objetivos sobre os demais (Saes, 2000).

No caso das organizações, existem mecanismos diferentes para coordenar essas ações no mercado. Esses mecanismos de incentivo e controle são alguns dos utilizados nas organizações, para que elas possam atingir seus objetivos.

O sucesso da adoção de uma política patrocinada pelo setor privado depende da homogeneidade de interesses, da capacidade de negociação e do encaminhamento da solução de conflitos. De acordo com o perfil das empresas que estão sendo representadas por elas, as organizações têm maior potencial de ação. As empresas que representam interesses homogêneos devem agir mais focadas, do que as que representam segmentos mais heterogêneos. Assim, se houver coordenação entre as 
ações nas organizações, haverá redução nos conflitos e, consequentemente, o desempenho de seus agentes tornará mais eficiente.

\section{Metodologia}

A presente pesquisa utilizou técnicas de coleta de dados, a análise documental. Conforme lembraram Ludke e André (1986), esta foi empregada porque dela podem ser extraídas poderosas evidências que fundamentam as afirmações do pesquisador. Inicialmente, consideramse, no caso deste estudo, instituições como Embrapa Pantanal, SEPROTUR - Secretaria de Produção e Turismo, Secretaria de Piscicultura e Pesca - SEAP, Secretaria de Meio Ambiente - SEMA e MAPA - Ministério da Agricultura, Pecuária e Abastecimento, MDAMinistério do Desenvolvimento Agrícola, além de órgãos oficiais de estatísticas, como o Instituto Brasileiro de Geografia e Estatística (IBGE).

\section{Resultados e discussões}

\subsection{Ambiente institucional da piscicultura}

O ambiente institucional rege as regras do jogo na piscicultura, no qual estão inseridos os agentes econômicos que compõem a piscicultura e também as particularidades que esses agentes possuem em sua área de atuação. Existem regras comuns para todos os agentes, independentemente de sua função ou área de atuação, como, por exemplo, a legislação, as políticas públicas de financiamento e as variáveis macroeconômicas.

De acordo com Williamson (2000), as ações políticas e legais são formadas pelo conjunto de normas e regras que delimitam as ações estabelecidas pelo homem, disciplinando suas ações com os semelhantes e com o mundo e também regulamentando outras instituições, definindo critérios que serão 
estabelecidos por meio das duas formas de regras - formais ou informais. A piscicultura é diretamente afetada por essas regras e leis de solo, água, meio ambiente, conservação de recursos naturais, caça e pesca, sanidade animal, leis de saúde pública, sanitárias, exportação e importação, leis tributárias, dentre outras. No conjunto da legislação brasileira, verificase a larga utilização de atos administrativos e normativos que regulamentam a organização da piscicultura brasileira, tais como decretos, portarias, resoluções e deliberações.

No que diz respeito à legislação ambiental em Mato Grosso do Sul, o estudo realizado por Rotta (2003) inclui o levantamento dos aspectos mais importantes a serem levados em conta, para que a piscicultura seja realizada de forma organizada e sustentável. Existem leis estaduais que regulamentam as alterações no meio ambiente, estabelecendo normas de proteção ambiental e outras providências.

Entretanto, o estado, como o resto do país, apresenta grande número de empreendimentos informais, não pelo fato do desinteresse do produtor em estar em dia com suas obrigações, mas porque, na prática, ocorre um conflito de competência ou duplicidade de regulamentação, como é o caso entre IBAMA, Departamento de Pesca e Piscicultura do Ministério de Agricultura (recentemente transformado em Secretaria Especial de Piscicultura e Pesca) e Secretaria de Estado de Meio Ambiente (SEMA) / Instituto do Meio Ambiente- Pantanal (IMA-P) do Mato Grosso do Sul (SEAP, 2008).

Justifica-se, plenamente, o cuidado de não serem introduzidas espécies exóticas no estado (Decreto Estadual $\mathrm{n}^{\circ} 5.646$, de 28 de setembro de 1990 , art.14, parágrafos $1^{\circ}$ e $2^{\circ}$ ), pois não há metodologia científica conhecida para se avaliar, antecipadamente, o impacto da introdução de espécies exóticas, visto que, uma vez introduzidas, não é mais possível removê-las. Pode-se citar, como um importante evento, a introdução do tucunaré, peixe da bacia Amazônica que conseguiu colonizar algumas regiões do Pantanal, exemplo típico de introdução negativa por meio da piscicultura (Prochmann, 2007). 
A legislação ambiental estadual (Lei no 1653 , de 10 de janeiro de 1996, art.15, alínea V) sugere a possibilidade de a piscicultura gerar efluentes poluentes nos cursos naturais de água. Tal fato, no entanto, possui pouca importância no estado, já que a produção predominante de peixes em viveiros convencionais, com baixo fluxo de água, gera comprovadamente poucos efluentes. São, portanto, considerados de baixo impacto ambiental.

Entretanto, se os projetos forem dimensionados adequadamente, sobretudo nos ambientes onde serão inseridos, esses sistemas de cultivo não se tornarão uma ameaça. Os tanques-redes são também mais perigosos quando de introdução de doenças e de espécies exóticas, pois o sistema tem contato direto com o ambiente e com os peixes nativos circunvizinhos. Porém, o cultivo em viveiros também possui essa mesma característica, visto que a água, que é descartada do cultivo, carrega todos os organismos patogênicos, que, se presentes, contaminam o curso d'água no qual esses efluentes são destinados. Em face do exposto, a única forma de evitar tais impactos é a prevenção, conforme previsto na lei. Nesse aspecto, os interesses de piscicultores e ambientalistas coincidem, uma vez que o instrumento legal já existe, porém necessita ser regulamentado e colocado em prática.

São de suma importância a regulamentação e o cumprimento dessas leis e decretos, para o aumento da competitividade e manutenção da piscicultura; no entanto, existem outros fatores institucionais que influenciam essa competitividade, como as políticas macroeconômicas, que são decisivas para alavancar o crescimento da atividade da piscicultura. Para que se possa entender tal contexto, faz-se necessário estudar as linhas de crédito aplicáveis em piscicultura, algumas delas bastante interessantes do ponto de vista financeiro. As principais são o Fundo Constitucional de Financiamento do Centro-Oeste - FCO, o Programa Nacional de Fortalecimento da Agricultura Familiar do Ministério do Desenvolvimento Agrário - PRONAF e o Programa de Geração de Emprego e Renda - PROGER, todas de origem federal e operacionalizadas pelo Banco do Brasil. 
O FCO foi um importante meio de financiamento de piscicultura em Mato Grosso do Sul, visto que foi responsável por grande parte dos projetos existentes. O programa de Desenvolvimento Rural proporciona taxas de financiamento, em média, de $8 \%$ a.a., corrigido com base no Índice Geral de Preços/Disponibilidade Interna - IGPD/DI da Fundação Getúlio Vargas, com prazos que podem chegar a doze anos, dependendo do projeto (MDA, 2008). (Sde

O PRONAF é outra linha de crédito que se destina a produtores familiares, cooperativas e associações. Entre as maiores vantagens dessa linha, está a possibilidade de financiar 100\% do investimento, com taxas similares às do FCO e rebate de $60 \%$ aplicados sobre os encargos financeiros (a opção mais barata no mercado), com oito anos para pagamento. Esses recursos estão previstos para serem aplicados em 54 municípios do Estado (MDA, 2008).

O prazo de financiamento pode também chegar a oito anos, e os encargos baseiam-se na taxa de juros de longo prazo - TJLP, acrescidos de $6 \%$ a.a. Apesar de os recursos serem provenientes de fundos do governo, os riscos das operações são integralmente do Banco do Brasil, o que justifica as diversas exigências cadastrais. Entre essas exigências, a que representa um dos maiores impeditivos do acesso ao crédito é o volume de garantias reais a ser negociado, o que pode chegar a $200 \%$ do valor a ser financiado. Uma decisão dos produtores é não solicitarem financiamentos para a produção, com exceção dos criadores de alevinos, que utilizam o FCO como instrumento de viabilização da atividade (Pochmann, 2003).

Além dos recursos já existentes, o governo federal desenvolve ações sociais que, por meio do Plano Nacional da Pesca, prevêem investimentos de $\mathrm{R} \$ 1,7$ bilhão ao longo dos próximos quatro anos, buscando o desenvolvimento da piscicultura, e mais linhas de crédito de $\mathrm{R} \$$ 1bilhão/ ano, com o intuito de proporcionar um crescimento de, aproximadamente, $40 \%$ até 2011 (SEAP, 2008). 
De acordo com Leão (2008), essas ações desempenhadas no ambiente institucional, tais como legislação, mudanças, regulamentações governamentais e formas de financiamento, indicam alterações na identificação da melhor forma de governança para os agentes e estão diretamente ligadas a seu desempenho econômico.

Portanto conclui-se que existem diversos incentivos ao desenvolvimento da piscicultura que podem alavancar a atividade no estado, visto que o crédito oferecido aos produtores possui bons prazos e taxas de juros a valores abaixo do oferecido pelo mercado. As exigências para contratação, porém, representam um entrave à obtenção dessas linhas de crédito, pois as garantias solicitadas ainda limitam os interessados na contratação.

Alternativas como linhas de crédito destinadas a pequenos empreendimentos podem ser estudadas e apresentadas, principalmente devido ao fato de a maioria dos empreendimentos no estado ser classificada como de pequeno porte.

\subsection{Ambiente organizacional da piscicultura}

O ambiente organizacional da piscicultura em Mato Grosso do Sul compõese de entidades tanto públicas quanto privadas. No Quadro 1, estão representados os órgãos ativos em iniciativas de coordenação para a piscicultura. 
Mônica Ferreira Satolani, Cynthia Cândida Corrêa \&

Mayra Batista Bitencourt Fagundes

Quadro 1: Principais componentes do ambiente organizacional da piscicultura em Mato Grosso do Sul.

\begin{tabular}{|c|c|}
\hline Elos da Cadeia & $\begin{array}{l}\text { Órgãos de Classe / Associações privadas / Órgãos } \\
\text { governamentais }\end{array}$ \\
\hline Piscicultura & $\begin{array}{l}\text { SEAP-Secretaria de piscicultura e pesca, Embrapa Pantanal, } \\
\text { SEBRAEMS, SENAI, SENAR, SEPROTUR- Secretaria de } \\
\text { Produção e turismo, SEMA- Secretaria de Estado de Meio } \\
\text { Ambiente, IMA-P- Instituto do Meio Ambiente- Pantanal, } \\
\text { IBAMA, IDATERRA, IAGRO. }\end{array}$ \\
\hline Abate / Frigorífico & Frigorífico de Peixes Mar \& Terra \\
\hline Distribuição & $\begin{array}{l}\text { Grandes produtores e corvênios com empresas aéreas e } \\
\text { terrestres. }\end{array}$ \\
\hline
\end{tabular}

Fonte: IEL (2000).

Ressalta-se, também, a importância de organizações como Câmara Setorial da Cadeia Produtiva da Piscicultura (SEAP) - Secretaria de piscicultura e pesca, hoje reconhecida como Ministério da Pesca. O delineamento de futuras ações para setor é feito por meio do debate entre governo e representantes da piscicultura, com o intuito de fomentar a atividade, a exemplo do Plano Nacional da Pesca, cujos investimentos serão de $\mathrm{R} \$ 1,7$ bilhão ao longo dos próximos quatro anos e cujas linhas de crédito serão de $\mathrm{R} \$ 1$ bilhão/ano até 2011 (SEAP, 2008).

A Embrapa Pantanal também se destaca com pesquisas na área de piscicultura e recursos pesqueiros, em especial, com ênfase em peixes nativos de maior interesse econômico e em sistemas de cultivo menos impactantes, com vistas em buscar condições para suprir as crescentes demandas do mercado e as exigências ambientais e contribuir ainda mais para acelerar a velocidade do processo de consolidar a Piscicultura, tanto no estado quanto no Brasil. Esse processo já está em curso, dada a execução de projetos nas linhas de sanidade, genética, reprodução, nutrição e sistemas de produção e tecnologia pós-colheita. 
O IBAMA, órgão responsável pela legislação ambiental, também fiscaliza os empreendimentos, quanto ao cumprimento da legislação e ao controle dos recursos naturais utilizados.

Órgãos como IAGRO e IDATERRA, ligados à Secretaria de Desenvolvimento Agrário e Assistência Técnica e Extensão Rural, proporcionam também orientação e suporte aos produtores rurais do estado (Leão, 2008).

Órgãos e agentes financiadores de pesquisa (MCT, CNPq, Finep etc) também contribuem para o desenvolvimento sustentável da piscicultura no estado e no Brasil, incentivando, em parceria com universidades, o melhoramento da atividade. Paralelamente, há projetos de fortalecimento, como o desenvolvido pelo estado de Mato Grosso do Sul, denominado “Peixe Vida", instituído pelo Decreto n. 9.845, de 10 de março de 2000. Iniciado pela SEPROTUR, o objetivo é incentivar os produtores rurais a se dedicarem à exploração da atividade de confinamento de peixes, dando prioridade àqueles que a executam em regime de economia familiar. $\mathrm{O}$ incentivo consistia na concessão de benefícios fiscais aos produtores rurais cadastrados no projeto.

Na condição de beneficiários deste projeto, com o intuito de fortalecer a piscicultura, estão somente os produtores rurais que cumprirem os requisitos legais exigidos para a exploração da atividade de piscicultura. É necessário o cadastramento por meio de empresa ou de profissional autônomo habilitado na atividade, na condição de responsável técnico pelo empreendimento. O cadastro será aprovado pelos técnicos das repartições gerenciadoras e deferido pela Secretaria de Estado de Fazenda.

Com vistas em executar a exploração da piscicultura em níveis compatíveis com normas legais disciplinadoras na produção de alimentos de origem animal, tornou-se necessário aos participantes regularizar as obrigações fiscais perante a Secretaria de Estado de Fazenda, mesmo que nenhum beneficiário estivesse associado a outros incentivos fiscais relacionados 
com a piscicultura, buscando também atender à legislação relativa, à manutenção de áreas de preservação permanente ou apresentar, alternativamente, correção das irregularidades, aprovado por órgão competente e sujeito à apreciação pela Secretaria de Estado da Produção e Turismo (SEPROTUR) ou pela Secretaria de Estado de Meio Ambiente (SEMA). É necessária também a autorização do órgão competente para o exercício da atividade de piscicultura.

A piscicultura, no estado, também conta com o apoio de entidades como SEBRAE/MS, SENAI e SENAR, que, por meio de treinamentos e cursos de capacitação para criação, manutenção e processamento do pescado, buscam incentivar o fomento da atividade na região do Pantanal, cujas características são extremamente favoráveis ao desenvolvimento da atividade (Leão, 2008).

Com a instalação de um frigorífico de peixes, chamado Mar \& Terra, localizado na cidade de Itaporã, novas perspectivas surgiram para os produtores da região. O Frigorífico fica na Fazenda Mar \& Terra, local onde cerca de 400 mil peixes já estão sendo criados e preparados para o abate.

Com o intuito de produzir cortes de carne de apenas quatro espécies de peixes nativos, como pacu, piauçu, piraputanga e pintado, considerada a espécie mais nobre, por ter carne saborosa e de qualidade, a produção passou a ser comercializada para os estados das regiões Sudeste, CentroOeste e Sul, sendo boa parte dos compradores, constituída de grandes redes de supermercados, que também têm o intuito de exportar para países como os EUA, França, Alemanha e Reino Unido.

O frigorífico tem uma área total de 1900 m2, enquanto na fazenda são cerca de 160 hectares de lâminas d'água para criação e engorda das espécies antes do abate. Na construção do frigorífico foram investidos mais de $\mathrm{R} \$ 6$ milhões de reais, provenientes do Fundo Constitucional de Investimentos do Centro-Oeste - FCO, e da empresa paulistana de investimentos Axial. 
Faz-se necessário relatar o caso de uma empresa familiar, responsável por grande parte do desenvolvimento da piscicultura no estado de Mato Grosso do Sul, denominada Projeto Pacu, dedicada à reprodução de peixes nativos, cujo pioneirismo, atrelado a fortes investimentos em pesquisa, resultou anualmente em produções de alto padrão de qualidade e em larga escala. Além do comércio de alevinos nos mercados interno e externo, atua também em projetos de repovoamento, ordenamento de cadeia produtiva, transferência de tecnologia em produção de peixes e na comercialização do filé de pintado.

O Projeto Pacu foi pioneiro no desenvolvimento de tecnologia para reprodução de peixes brasileiros e iniciou suas pesquisas com peixes onívoros, mais precisamente com as espécies pacu, peal e corimbatá. Logo que essas espécies foram reproduzidas com sucesso, começaram as pesquisas para espécies mais exigentes, como piraputanga, piracanjuba e matrinxã. O grande salto tecnológico foi o desenvolvimento das técnicas de reprodução dos grandes carnívoros, pintado e dourado. Em meio a este trabalho, inúmeros outros peixes foram reproduzidos, como os bagres jaú, jurupensen, jurupoca e pirara. Ao todo, o Projeto Pacu desenvolveu 20 pacotes tecnológicos, além de incorporar e desenvolver métodos construtivos para a piscicultura brasileira. Com esta empresa, pioneira no setor, surgiram inúmeros produtores de peixes, pesque-pague, frigoríficos e fábricas de ração em todo o Brasil.

O ambiente organizacional da piscicultura, como relacionado acima, é formado por diversos agentes, tanto públicos quanto privados. As relações estabelecidas entre eles são identificadas como formais, como as relações entre universidades e órgãos de pesquisa, como a exemplo do MCT, CNPq e Finep, que, por meio de incentivo à pesquisa, desenvolvem técnicas de aperfeiçoamento e manejo para produção, contratos de financiamentos e linhas de crédito com bancos oficiais, contratos para distribuição de alevinos com empresas aéreas, ou contratos de comercialização com frigoríficos (Leão, 2008). Segundo a autora, as transações realizadas por meio de contratos informais são, por exemplo, a compra de alevinos ou de ração entre os produtores, a qual, geralmente, 
Mônica Ferreira Satolani, Cynthia Cândida Corrêa \&

Mayra Batista Bitencourt Fagundes

é de pequeno e médio porte, via telefone ou pessoalmente, sem assinatura de papéis. Atividades de consultoria, como os desenvolvidos por órgãos como o SEBRAE, que incentivam, por exemplo, o desenvolvimento de artesanato local, também não utilizam meios formais para o desempenho.

Conclui-se, portanto, que o ambiente organizacional da piscicultura está diretamente ligado ao desempenho e à manutenção na atividade, visto que os agentes que integram esse ambiente são de vital importância para a continuidade e manutenção da piscicultura no estado de Mato Grosso do Sul. Deve-se ressaltar, ainda, que são diretamente responsáveis pela coordenação de ações, mecanismos de incentivos, pesquisa e extensão e homogeneidade da cadeia.

\section{Conclusão}

Em virtude das condições ideais de clima e da grande quantidade de água doce, o Estado de Mato Grosso do Sul possui um dos maiores potenciais nacionais para o desenvolvimento da piscicultura, além de possuir boa capacidade de fornecimento e estrutura de produção de alevinos e engorda de peixes. O estado é também um grande produtor de insumos básicos de rações para peixes, e resultados econômicos e financeiros favoráveis aos investimentos realizados no estado, além de se ter uma capacidade técnica e volume para exportar e apoio institucional à pesquisa e desenvolvimento da atividade.

Verificou-se, por meio deste estudo, a existência de entidades públicas que destinam linha de financiamento, linhas de crédito, mesmo que apresentem dificuldades e exigências que dificultam sua contratação, mas são de grande relevância para o desenvolvimento da piscicultura no Estado. Destacam-se, também, entidades que desenvolvem pesquisa e extensão, e a importância de órgãos que fiscalizam o cumprimento da legislação ambiental vigente. A atividade impacta diretamente o ecossistema regional e há preocupação em regulamentar e tornar cada vez mais sustentável a exploração de tal atividade. Todo este conjunto 
forma os ambientes institucional e organizacional da cadeia da piscicultura em Mato Grosso do Sul, os quais afetam o desempenho econômico da atividade, pois suas ações são diretamente responsáveis e vitais para a manutenção da Piscicultura.

Pode-se concluir, portanto, que a cadeia da piscicultura no estado de Mato Grosso do Sul apresenta grandes possibilidades de crescimento e ampliação, mas seria oportuna uma discussão sobre os efeitos dos ambientes tecnológicos e competitivos no desempenho dessa atividade, mostrando ainda as estruturas de governança, bem como os custos de transação envolvidos, para mensurar, com mais precisão, o desempenho da piscicultura no Estado de Mato Grosso do Sul. Portanto, este estudo representa uma discussão preliminar da aplicação da teoria da Nova Economia Institucional, em suas duas correntes.

\section{Referências}

CYRINO, J. E. P. Sistemas de Produção em Piscicultura. Fundação de estudos agrários Luiz de Queiroz, USP, Piracicaba, 1996.

EMBRAPA - Empresa Brasileira de Pesquisa Agropecuária. Piscicultura. Disponível em: <http://embrapa.gov.br>. Acesso em: 08 mai. 2008.

FARINA, E. M. M. Q. Competitividade e coordenação de sistemas agroindustriais: um ensaio conceitual. Gestão \& Produção, São Carlos, v. 6, n. 3, p. 147-161, dez. 1997.

FARINA, M.; REARDON, T. "Agrifood Grades and Standards in the Extended Mercosur: their Role in the Changing Agrifood System". American Journal of Agricultural Economics, 1999.

LÜDKE, M.; ANDRÉ, M.E.D.A. Pesquisa em educação: abordagens qualitativas. São Paulo: EPU, 1986. 
Mônica Ferreira Satolani, Cynthia Cândida Corrêa \&

Mayra Batista Bitencourt Fagundes

MATTHEWS, R. C. O. The economics of institution and the source of growth. Economics Journal, New York. v. 96, n. 384, p. 903-918, Dec. 1986.

MDA- Ministério do Desenvolvimento Agrícola. Plano de Safra 2008/ 09. Disponível em: <http://www.mda.gov.br>. Acesso em: 10 mai. 2008.

NORTH, D. Custos de transação, instituições e desempenho econômico. Rio de Janeiro: Instituto Liberal, 1994.

PROCHMANN, A. M. Estudo da cadeia produtiva da piscicultura. Campo Grande: UFMS: SEPROD: SERC: Fundação Cândido Rondon, 76 p. (no prelo)

ROTTA, M. A. Situação da Piscicultura Sul-mato-grossense suas Perspectivas no Pantanal. Embrapa Pantanal, 2003. Disponível em: <http://www.cpap.embrapa.br>. Acesso em: 13 mar. 2008.

SAES, M. S. M. Organizações e Instituições. In: ZYLBERSZTAJN, D.; NEVES, M. F. (Org.) Economia e gestão de negócios agroalimentares. São Paulo: Pioneira, 1999.

SECRETARIA DE ESTADO DE PRODUÇÃO DE MATO GROSSO DO SUL. Caracterização, diagnóstico e projeto de fortalecimento da piscicultura no Estado de Mato Grosso do Sul. Campo Grande: SEPROD/MS, 1999. 80 p. (não publicado).

SOUZA FILHO, J.; SCHAPPO, C.L.; TAMASSIA, S.T.J; BHORCHARDT. Estudo de competitividade da piscicultura no Alto do Vale do Itajaí. Florianópolis: Instituto CEPA/SC/Epagri/Acaq, 2002, $76 \mathrm{p}$.

ZIMMERMANN, S. Fundamentos da Moderna Piscicultura. $1^{\mathrm{a}}$ ed. Brasília: ULBRA, 2001. 
WILLIAMSON, O. E. The new institutional economics: taking stock, looking ahead. Journal of Economic Literature, Stanford, v. 38, n. 3, p. 595-613, Sep. 2000.

\begin{abstract}
The pisciculture can be a gear lever of social and economical development, making possible the effective utilization of the local natural resources, principaly the hídricos and the creation of positions of salaried works. However, countless variables that condition exist or they affect the success of a rural enterprise. In that sense, the present study has as objective demonstrates the organizational and institutional factors capable to affect the development of the fish farming in the state of Mato Grosso do Sul. For so much, it was looked for to investigate as the institutions that compose the organizational and institutional atmospheres affect directly and they influence in the growth or direcionamento of the chain in the State. For accomplishment of this work it was used as technique of collection of data, the documental analysis, considering information collected directly in tied institutions the pisciculture as important supplier of data, moreover other public institutions. It can be concluded that the chain of the pisciculture in the state of Mato Grosso do Sul introduces an organized form, with great growth possibilities and enlargement, however, it exists the professionalization need and their agents' investments.
\end{abstract}

Keywords: pisciculture, institutional environment, organizational environment. 